\title{
Conservation of fluid and electrolytes by the human gut
}

\author{
G. E. SLADEN
}

From the Department of Gastroenterology, St Bartholomew's Hospital, London

The stomach, liver, and pancreas secrete large quantities of fluid and electrolytes into the upper gastrointestinal tract, mainly in the few hours after each meal. The remainder of the intestine plays a vital role in the conservation of this fluid. If this mechanism fails, massive quantities of fluid and electrolyte may be lost from the gut, leading to severe dehydration and acid-base disturbances. In this article, it is proposed to discuss the mechanisms whereby this reabsorption takes place and to indicate some ways in which it may become deranged.

Table I indicates the approximate quantities of water and the major monovalent ions handled by the adult gut in the course of an average 24 hours. From this it can be deduced that the gut may absorb approximately 9 litres of water, $1,000 \mathrm{~m}$-equiv of sodium, 900 m-equiv of chloride, and 100 m-equiv of potassium daily. The capacity for absorption is undoubtedly greater than this. Patients with diabetes insipidus may drink 15 or more litres of water daily without producing diarrhoea. The studies of Love, Mitchell, and Phillips (1968) suggest that the absorptive capacity of the adult gut is approximately 15-20 litres of water and 1,500-3,000 m-equiv sodium daily from isotonic saline administered by continuous jejunal perfusion. Isotonic saline given at more rapid rates is certainly a very effective purgative.

\begin{tabular}{|c|c|c|c|c|}
\hline & Water $(m l)$ & $\begin{array}{l}\text { Sodium } \\
\text { (m-equiv) }\end{array}$ & $\begin{array}{l}\text { Chloride } \\
\text { (m-equiv) }\end{array}$ & $\begin{array}{l}\text { Potassium } \\
\text { (m-equiv) }\end{array}$ \\
\hline $\begin{array}{l}\text { Input } \\
\text { Diet } \\
\text { Gut secretions }\end{array}$ & $\begin{array}{l}1,500 \\
7,500\end{array}$ & $\begin{array}{r}150 \\
1,000\end{array}$ & $\begin{array}{l}150 \\
750\end{array}$ & $\begin{array}{l}80 \\
40\end{array}$ \\
\hline Total & 9,000 & 1,150 & 900 & 120 \\
\hline $\begin{array}{l}\text { Output } \\
\text { Ileostomy } \\
\text { Faeces }\end{array}$ & $\begin{array}{l}450 \\
150\end{array}$ & $\begin{array}{r}60 \\
5\end{array}$ & $\begin{array}{r}45 \\
3\end{array}$ & $\begin{array}{r}4 \\
12\end{array}$ \\
\hline
\end{tabular}

Table I Approximate mean quantities of water, sodium, chloride, and potassium handled by the gut in 24 hours in normal subjects and in patients with established ileostomy

${ }^{1}$ Dat a obtained from Wilson (1962), Kramer et al (1962), and Wrong et al (1965).
A comparison of gut losses in normal subjects and those with established ileostomy (Table I) suggests that the bulk of this absorption takes place in the small intestine. The colon would appear to be responsible for absorbing approximately $300 \mathrm{ml}$ of water and 50 m-equiv of sodium and chloride, and it secretes small amounts of potassium. This is, of course, an oversimplification because the ileum can adapt to the absence of a colon by increasing its absorption of sodium and water (Wright, Cleveland, Tilson, and Herskovic, 1969). There is now direct evidence that the amounts of water, sodium, and chloride passing from ileum to colon in health are approximately two or three times those observed in most patients with ileostomy (Giller and Phillips, 1970). Nevertheless, the bulk of absorption takes place in the small intestine. Failure of smallintestinal absorption will allow large quantities of fluid to enter the colon, whose absorptive capacity may be quite easily overwhelmed. On the basis of continuous colon perfusion studies, Shields and Miles (1965) estimated that the normal colon has the capacity to absorb approximately $3,000 \mathrm{ml}$ of water and 450 m-equiv of sodium daily.

The sites and mechanisms of absorption will now be considered in more detail.

\section{Stomach and Duodenum}

Negligible absorption takes place from the stomach and indeed the gastric mucosa is relatively impermeable to the movement of water or sodium (Code, 1962). On the other hand, the duodenal mucosa is freely permeable and considerable movement of water and ions can occur in response to osmotic and concentration gradients (Hindle and Code, 1962; Reitemeyer, Code, and Orvis, 1957). This ensures that, by the time the upper jejunum is reached, the aqueous phase of intestinal contents is isotonic with plasma and consists largely of sodium, chloride, and bicarbonate (Fordtran and Locklear, 1966). The products of digestion of carbohydrate and protein make a relatively small contribution to this 
tonicity (less than $50 \mathrm{mOsm} / \mathrm{kg}$ ), irrespective of the nature of the meal.

Gastric emptying is partly regulated in such a way as to 'protect' the upper jejunum from grossly non-isotonic solutions. Hypertonic solutions leave the stomach more slowly than isotonic solutions and there is evidence that appropriate 'osmoreceptors' reside in the duodenal mucosa (Hunt, 1956; Elias, Gibson, Greenwood, Hunt, and Tripp, 1968). If this mechanism is impaired, as after various types of gastric surgery, large quantities of non-isotonic fluid may enter the upper jejunum after meals. Rapid luminal hydrolysis of proteins and starch may then produce a markedly hypertonic solution. which encourages the bulk movement of water across the permeable duodenal mucosa (Sessions, Reynolds, Ferguson, and Scott, 1962). This may be partly responsible for the fluid diarrhoea that occurs in some patients with the early dumping syndrome, but undoubtedly this is not the only or even the most important mechanism.

Little or no net absorption of fluid takes place in the duodenum from isotonic solutions. It is essentially a region for the efficient mixing of food and upper gut secretions and for the rapid equilibration of tonicity and ionic composition of luminal contents. Excessive upper gut secretions may theoretically overwhelm the absorptive capacity of the lower regions of the intestine and lead to fluid loss from the gut. This may be a partial explanation of the fluid diarrhoea observed in some patients with gastrin-secreting islet cell tumours of the pancreas ('Zollinger-Ellison syndrome'). It has been postulated that the analagous syndrome of watery diarrhoea and achlorhydria results from the production of secretin or a secretin-like hormone by similar pancreatic tumours (Kraft, Tompkins, and Zollinger, 1970). In some patients excessive basal secretion of pancreatic juice has been observed (Sircus, Brunt, Walker, Small, Falconer, and Thomson, 1970) and may be directly responsible for the fluid losses, which are sometimes massive.

\section{Jejunum}

The intubation studies of Borgström, Dahlqvist, Lundh, and Sjövall (1957) suggested that the bulk of absorption of protein, starch, and fluid was performed by the proximal $100 \mathrm{~cm}$ (or half) of the small intestine. The jejunum is, therefore, able to absorb large quantities of water and sodium from a solution which is essentially isotonic saline. However, perfusion of the upper jejunum with saline at $15-20 \mathrm{ml}$ per minute produces fluid diarrhoea and very little absorption can be demonstrated (Sladen and Dawson, 1969a). Indirect evidence suggests that these rates are approximately physiological in 0 the postprandial phase. Various substances in the jejunal lumen can promote efficient net absorption $\frac{\mathrm{O}}{-}$ of sodium and water and may be important physio- $\overrightarrow{\vec{F}}$ logically in securing this absorption in the few hours $\stackrel{?}{+}$ after each meal.

Glucose, at concentrations of $14 \mathrm{mM}(250 \mathrm{mg} \%) \frac{\overline{0}}{\bar{c}}$ or more, promotes the absorption of sodium, $\vec{\nabla}$ chloride, and water from isotonic solutions and $\varrho$ maximum rates are obtained from solutions containing approximately $56 \mathrm{mM}$ or $1 \%$ glucose (Sladen $\overrightarrow{0}$ and Dawson, 1969a). Galactose and maltose have a very similar effect, whereas fructose is much less $\vec{\omega}$ effective in this respect (Fig. 1). Galactose and? glucose share a common transport mechanism in the intestinal mucosa, whereas fructose is absorbed by a ${ }_{\omega}$ separate mechanism of uncertain nature (Holds- ir worth and Dawson, 1964). This suggests that there $\overrightarrow{-}$ is a link between the glucose-galactose transport 8 system and the mechanism whereby sodium and $\mathrm{O}$ water are absorbed by the jejunum. The nature of this link is uncertain. There is evidence from animal $c_{\Omega}$ studies that glucose may directly promote the active transport of sodium against concentration and elec- ֶㅡㄹ trical gradients (Schultz and Zalusky, 1964; Barry, Smyth, and Wright, 1965). Furthermore, luminal $\vec{\varphi}$ sodium is obligatory for the active transport of glucose out of the jejunal lumen in man (Olsen ant

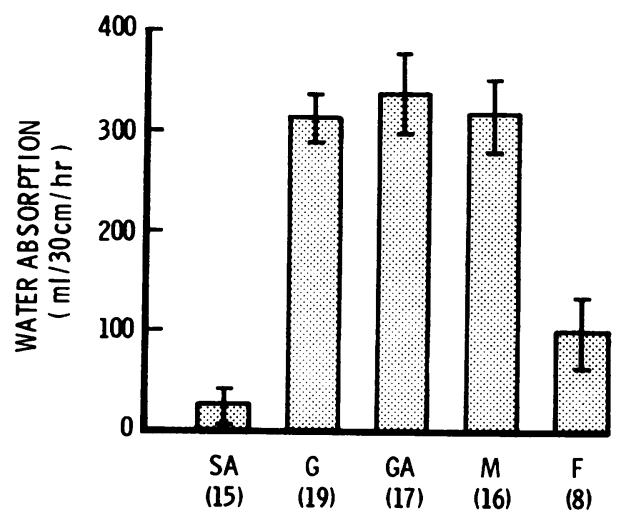

$S A=$ Saline, $G A=$ Galactose,$F=$ Fructose $G=$ Glucose, $M=$ Maltose

Fig. 1 Mean water absorption rates from isotonic saline and a series of isotonic sugar-saline mixtures containing $2.5 \%$ sugar. $S A=$ saline; $G=$ glucose; $\boldsymbol{G A}=$ galactose $; M=$ maltose $;=$ fructose; bracketed numbers $=$ number of individuals studied; bars indicate \pm 1 SEM. Solutions were perfused at $20 \mathrm{ml}$ per minute through a $30 \mathrm{~cm}$ segment of upper jejunum in normal subjects using a double-lumen tube. Data taken from Holdsworth and Dawson (1964); McMichael Webb, and Dawson (1967); Sladen and Dawson (1969a). 
Ingelfinger, 1968). Crane (1965) has postulated a mechanism whereby glucose and sodium combine with a common brush-border carrier, which facilitates the transport of both into the mucosal cell. Another possibility is that glucose transport generates the bulk flow of water out of the lumen and that sodium is absorbed passively by a process of convection in the stream of water ('solvent drag'). The jejunal mucosa is certainly permeable to passive movements of small ions and net absorption of sodium can be abolished or even reversed by appropriate manipulation of the magnitude and direction of water movement (Fordtran, Rector, and Carter, 1968).

Whatever the mechanism, the similar efficacy of maltose suggests that this process may be important physiologically. Whereas glucose and galactose do not normally accumulate in the intestinal lumen after meals, maltose is the major luminal end product of starch digestion. Some amino acids have a similar stimulant effect on sodium absorption in man (Adibi, 1970). It is, therefore, likely that absorption of the end products of carbohydrate and protein digestion plays an important physiological role in promoting the absorption of sodium and water by the jejunum.

Another important jejunal function is the efficient absorption of bicarbonate ions (Turnberg, Fordtran, Carter, and Rector, 1970). Bile and pancreatic juice are bicarbonate-rich and large quantities of this anion enter the upper intestine daily. Yet midjejunal contents contain little bicarbonate (Fig. 2). This avid absorption of bicarbonate is also coupled to the net absorption of sodium and water. Sladen and Dawson (1968) found that $30 \mathrm{mM}$ bicarbonate was as effective as $56 \mathrm{mM}$ glucose in promoting the jejunal absorption of sodium in man. The mechanisms are obscure and it is not certain if bicarbonate is transported as such out of the lumen or if hydrogen ion is secreted into the lumen to combine there with bicarbonate. Some evidence to favour the latter hypothesis has recently been produced (Turnberg et al, 1970). Again this coupling of bicarbonate absorption to that of sodium and water may be important physiologically in securing the postprandial conservation of fluid by the upper intestine.

Chloride absorption appears to follow that of sodium passively and the two ions are absorbed at equal rates from isotonic saline mixtures. However, from chloride-bicarbonate mixtures, chloride is usually absorbed less avidly than bicarbonate even when it is present in the lumen in higher concentration. Equilibrium concentrations of these anions in fluid perfusing the human jejunum are shown in Table II. The bicarbonate concentration is consider-

\begin{tabular}{lccc}
\hline Electrolyte & \multicolumn{3}{l}{ Concentration $($ m-equiv/l) } \\
\cline { 2 - 4 } & Jejunum & Ileum & Colon \\
\hline Sodium & 140 & 138 & 139 \\
Potassium & 6 & 6 & 13 \\
Bicarbonate & 6 & 40 & 103 \\
Chloride & 138 & 104 & 50 \\
\hline
\end{tabular}

Table II Equilibrium concentrations of sodium, potassium, chloride, and bicarbonate in fluid perfusing the normal human jejunum, ileum, and colon at 10-14 ml per minute

${ }^{1}$ These figures represent the concentrations of electrolytes which would be unaltered by passage through human small and large intestine at these rates. Data from Phillips and Summerskill (1967) and Billich and Levitan (1969).

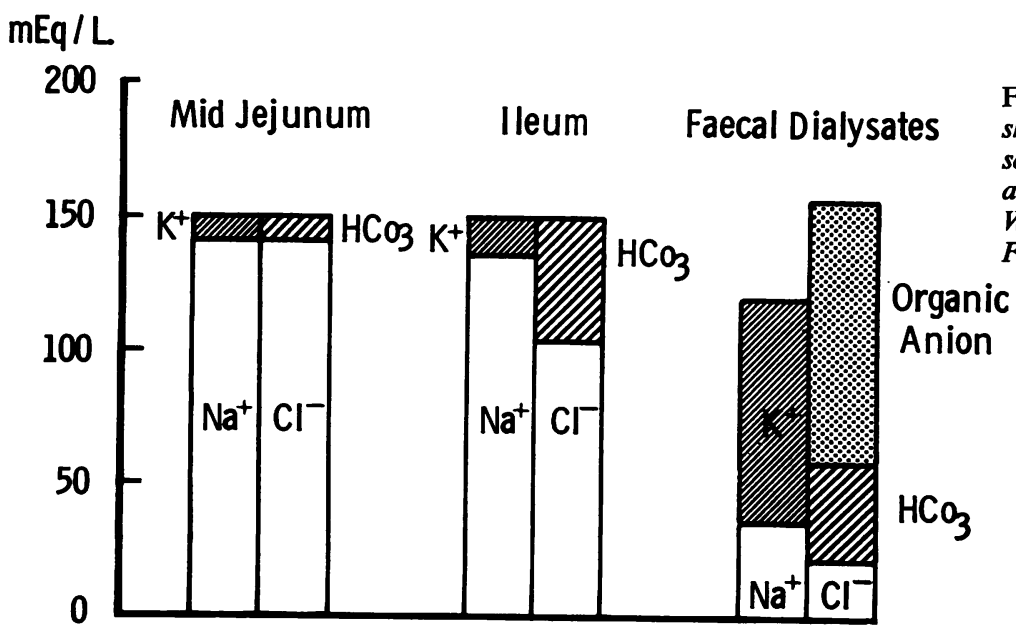

Fig. 2 Composite ionograms showing typical composition of fluid sampled at mid-jejunum and ileum and of faecal fluid. Faecal data from Wrong et al (1965). Other data from Fordtran and Ingelfinger (1968). 
ably less than that of the plasma, whereas the chloride concentration is greater. Chloride can enter the jejunal lumen in apparent exchange for bicarbonate, but the physiological relevance of this as a mechanism for bicarbonate absorption is uncertain.

The movements of potassium can generally be explained in terms of passive diffusion of the ion down electrochemical gradients through a permeable mucosa. The jejunum is polarized to a slight and variable extent, so that equilibrium potassium concentrations are close to plasma levels (Table II). Absorption occurs from higher luminal concentrations, but is relatively little influenced by changes in the net movement of water (Phillips and Summerskill, 1967).

Water absorption is also considered to be a passive process, consequent upon net movement of solute out of the lumen. Water accompanies solute in isotonic proportions when isotonic solutions are perfused through the human jejunum and there is no evidence that water can be absorbed in the absence of appropriate solute movement (Curran, 1968). Water will move in response to large osmotic gradients between lumen and plasma, but, for reasons already given, these do not normally occur physiologically.

Jejunal conservation of fluid is deranged in any condition of severe malabsorption due to mucosal disease. Specific sugar malabsorption, as in disaccharidase deficiency or glucose-galactose malabsorption, is commonly associated with fluid loss from the gut if enough of the offending sugar is consumed. This is largely the result of retention of considerable volumes of fluid in the small-intestinal lumen by the osmotic action of unabsorbed sugar (Launiala, 1968).

Cholera is the only specific, and most dramatic, derangement of the jejunal handling of water and electrolytes. In this condition massive quantities of fluid are secreted, mainly into the jejunum, and yet the mucosa is intact, glucose absorption is normal, and the mechanism linking sodium absorption to that of glucose is also intact (evidence reviewed by Sladen and Dawson, 1969b). The explanation of the massive secretion of fluid is hotly debated, but it is of great physiological and practical interest that the fluid losses can be significantly reduced by intestinal infusions of glucose or galactose-electrolyte mixtures (Hirschhorn, Kinzie, Sachar, Northrup, Taylor, Ahmad, and Phillips, 1968). Fructose does not have this effect in cholera, as might be expected from the physiological observations already discussed. Glycine is as effective as glucose and the combination of the two is apparently more effective than either alone (Nalin, Cash, Rahman, and Yunus, 1970). This suggests that amino acids and sugars promote sodium absorption by parallel and additive mechanisms and there is animal evidence to support this concept (Schultz and Zalusky, 1965).

\section{Ileum and Colon}

It is convenient to consider these regions together $\frac{\bar{c}}{\bar{c}}$ because they handle fluid and electrolytes in a similar fashion and quite differently from the jejunum. The absorption of water, sodium, andes chloride is independent of the presence of luminal $\vec{O}$ sugars and bicarbonate and, furthermore, the ionscan be absorbed against very large concentration $\vec{\omega}$ gradients between lumen and plasma (Fordtran et al, 1968; Devroede and Phillips, 1969). In both colono and ileum sodium can be absorbed from luminale concentrations as low as $\mathbf{4 0}$ m-equiv/ $\mathbf{l}$ and chloridecir is absorbed from even lower concentrations. These $\overrightarrow{-}$ regions are normally polarised electrically, thee plasma being positive to the lumen. Ileal potentials? of about $5 \mathrm{mV}$ are usually recorded (Fordtran et al, 1968), whereas colonic potentials are much higher $-c$ approximately $30-40 \mathrm{mV}$ (Geall, Spencer, and? Phillips, 1969). This means that sodium can be absorbed against both chemical and electrical gradients by some active transport process. $\mathrm{By}$ contrast the jejunum cannot absorb sodium from luminal concentrations less than 90-100 m-equin. even in the presence of glucose (Sladen and Daws 1969a).

Chloride is usually absorbed from the lower bowelo even more avidly than sodium. The excess chloride $\frac{\Omega}{\Phi}$ absorption from the colon is almost exactly balanced $\overrightarrow{\vec{F}}$ by the secretion of bicarbonate into the lumen? (Devroede and Phillips, 1969). Chloride may thus be absorbed both as the major accompanying aniono for sodium and by a process of anionic exchange with bicarbonate. This avid absorption of chloride, 0 of course, explains the well known observation that diversion of the urinary stream into the colon often. leads to severe hyperchloraemic acidosis. In theo course of this anion exchange process concentration gradients for chloride and bicarbonate develop옹 across the ileal and colonic mucosa, as shown by> the characteristic equilibrium concentrations of these anions in perfusing fluid (Table II). Bicarbon- $\bar{N}$ ate moves into the lumen against both concentration and electrical gradients, again suggesting some $\sim$ active transport process. However, the mechanism ${ }_{\omega}^{N}$ is uncertain and the exact nature of ion exchangeo processes is quite obscure.

Potassium movements in lower intestine, as in jejunum, are usually considered to be passive $\stackrel{\mathscr{P}}{+}$ (Fordtran and Dietschy, 1966) and can generally 0 be explained in terms of movement down concen- $\bar{O}$ tration and electrical gradients. The equilibrium 
concentration in the colon, shown in Table II, is to be expected if potassium can move freely into the lumen, which is $30-40 \mathrm{mV}$ negative to the plasma. Stool potassium concentrations are normally much higher than this. For example, using the technique of dialysis in vivo, Wrong, Metcalfe-Gibson, Morrison, $\mathrm{Ng}$, and Howard (1965) obtained a normal range of 30-147 m-equiv/l. This cannot be explained in terms of electrical gradients, but is probably the result of water absorption and the relative impermeability of the lower regions of the colon to the passive movements of potassium (Devroede and Phillips, 1970).

Water is absorbed passively as a result of net solute transport out of the lumen, as already discussed in relation to jejunal function. However, isotonic solutions perfusing ileum and colon often become hypotonic by about $10-20 \mathrm{mOsm} / \mathrm{kg}$, suggesting that there is some barrier to the free movement of water in response to local osmotic gradients (Whalen, Harris, Geenen, and Soergel, 1966, and personal observations).

Although the ileum and colon handle fluid in a similar fashion, the composition of ileal and faecal fluid is quite different (Fig. 2). In faecal fluid, sodium is almost replaced by potassium and chloride by a combination of bicarbonate and organic anion. The latter is derived largely from bacterial activity on undigested food residue (Rubinstein, Howard, and Wrong, 1969). Otherwise, these differences in composition are related to the relatively slow rate of transit of luminal contents through the colon. In
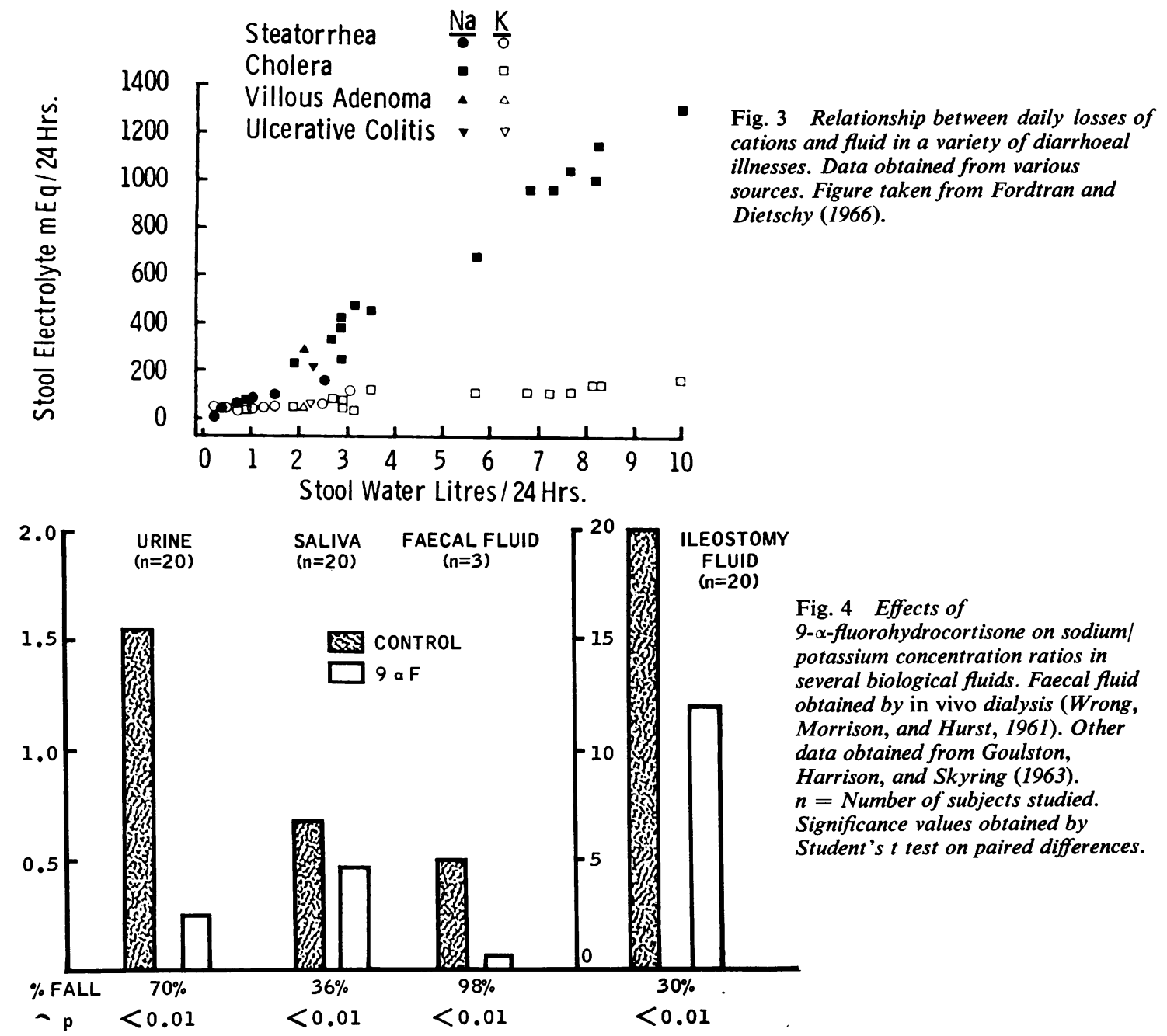

Fig. 4 Effects of 9- $\alpha$-fluorohydrocortisone on sodium/ potassium concentration ratios in several biological fluids. Faecal fluid obtained by in vivo dialysis (Wrong, Morrison, and Hurst, 1961). Other data obtained from Goulston, Harrison, and Skyring (1963). $n=$ Number of subjects studied. Significance values obtained by Student's $t$ test on paired differences. 
diarrhoeal illnesses, with rapid colon transit, these differences are abolished and, at rates of stool flow in excess of 3 litres per day, stool fluid closely resembles plasma or upper ileal contents in composition (Watten, Morgan, Songkhla, Vanikiati, and Phillips, 1959). In acute severe diarrhoeal states, the rate of sodium loss is directly proportional to stool flow rate, whereas potassium losses are smaller and relatively less affected by the rate of fluid loss (Fig. 3 ). The fluid is alkaline and acute metabolic acidosis will result. In chronic low grade diarrhoeal illnesses (less than $700 \mathrm{ml}$ per 24 hours), potassium is the major cation in the stool and potassium deficiency and metabolic alkalosis may ensue. This process is commonly aggravated by chronic excessive aldosterone production.

Aldosterone and other salt-active adrenal steroids have a pronounced effect on the ileal and colonic handling of sodium and potassium (Fig. 4). In the colon, perfusion studies have shown that these steroids promote net absorption of sodium, chloride, and water (Levitan and Ingelfinger, 1965; Levitan, 1967). In patients with primary aldosteronism excessive colonic secretion of potassium has been demonstrated (Shields, Miles, and Gilbertson, 1968). It seems likely that the primary effect of aldosterone is to stimulate the active transport of sodium out of the lumen and this is associated with an increased potential difference across the colonic mucosa

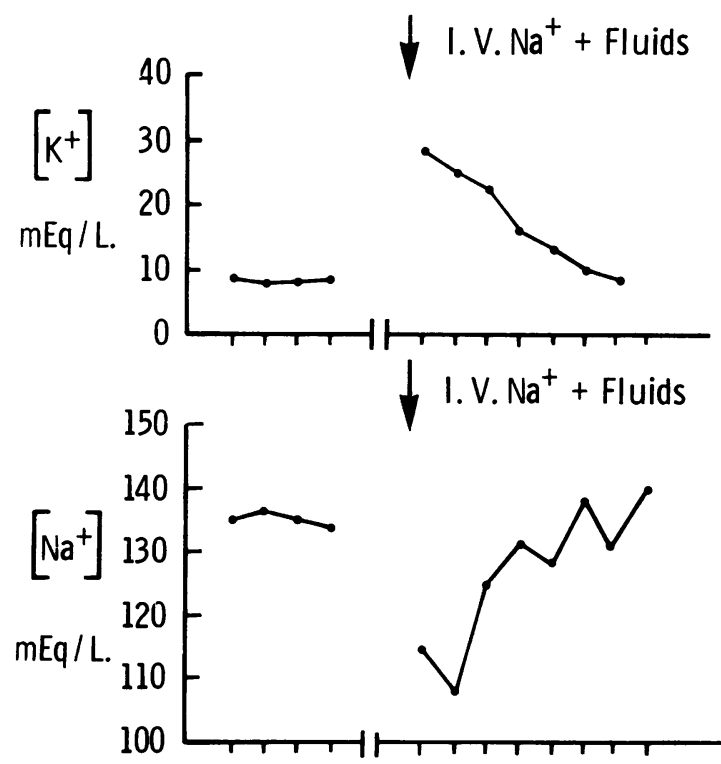

Fig. 5a. Days 1234

12345678
(Edmonds and Godfrey, 1970). Increased potassium 7 secretion may simply be the passive consequence of $\vec{F}$ this increased electrical gradient.

The avid absorption of sodium, under the influence $\vec{F}$ of aldosterone, enables the lower intestine to play a $\stackrel{?}{+}$ potentially important role in the conservation of ${ }^{\circ}$ fluid and sodium in adverse environmental condi- $\frac{\bar{V}}{\overline{0}}$ tions. However, normal faecal loss of sodium is so $\frac{\tilde{\sigma}}{\sigma}$ small that the contribution of the colon to conserva- $\stackrel{\mathbb{Q}}{\complement}$ tion in the face of sodium deprivation must be very limited. In patients with ileostomy or with chronic $\vec{O}$ diarrhoeal illnesses, gut losses of sodium are appreci- able and this has some important practical conse- $\vec{\omega}$

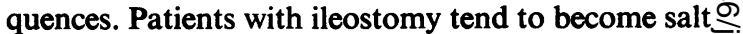
and water depleted, especially in hot climates (Clarke, $\frac{8}{8}$ Chirnside, Hill, Pope, and Stewart, 1967). They ¿s $^{\circ}$ have a greatly diminished capacity to respond í adequately to variations in the dietary sodium in- $\overrightarrow{-}$ take (Kramer, 1966). Restriction of sodium intake $\mathscr{E}$ results in some reduction of ileostomy sodium loss음 but may rapidly lead to severe salt depletion.Excessive sodium intake commonly produces a con- $c$ siderable increase in ileostomy losses of sodium and water. Thus, the normal small intestine has both a limited ability to conserve sodium and a limited ${ }^{2}$ capacity to absorb it. In attempting to conserve $\vec{\theta}$ sodium and water, in response to aldosterone secre-. tion, patients with ileostomy or diarrhoea will sufferp increased gut losses of potassium. In one subject,
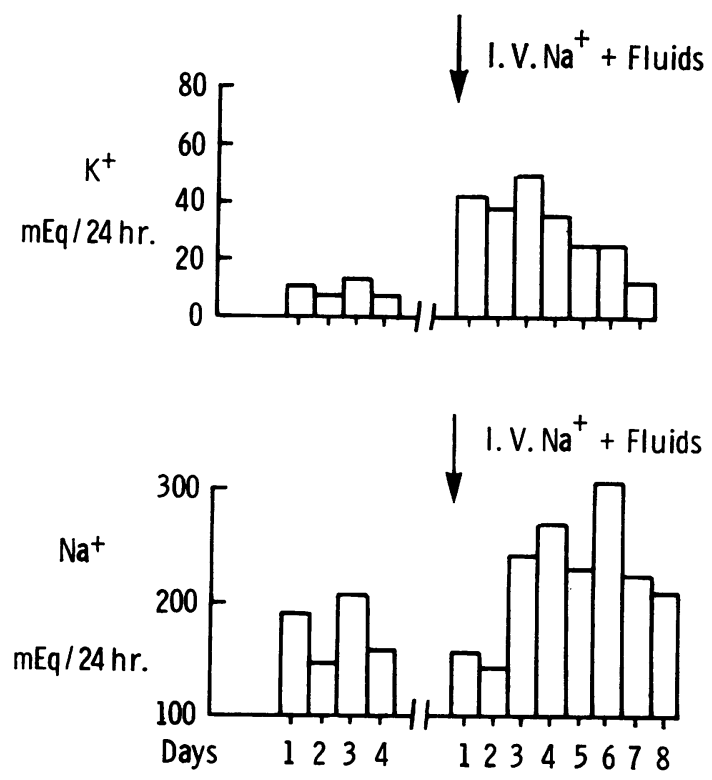

Fig. 5b.

Fig. 5 Cation concentrations (a) and amounts (b) in ileostomy effluent in a patient with severe ileostomy dysfunction before, during and after an episode of serious salt and water depletion (personal unpublished observations). 


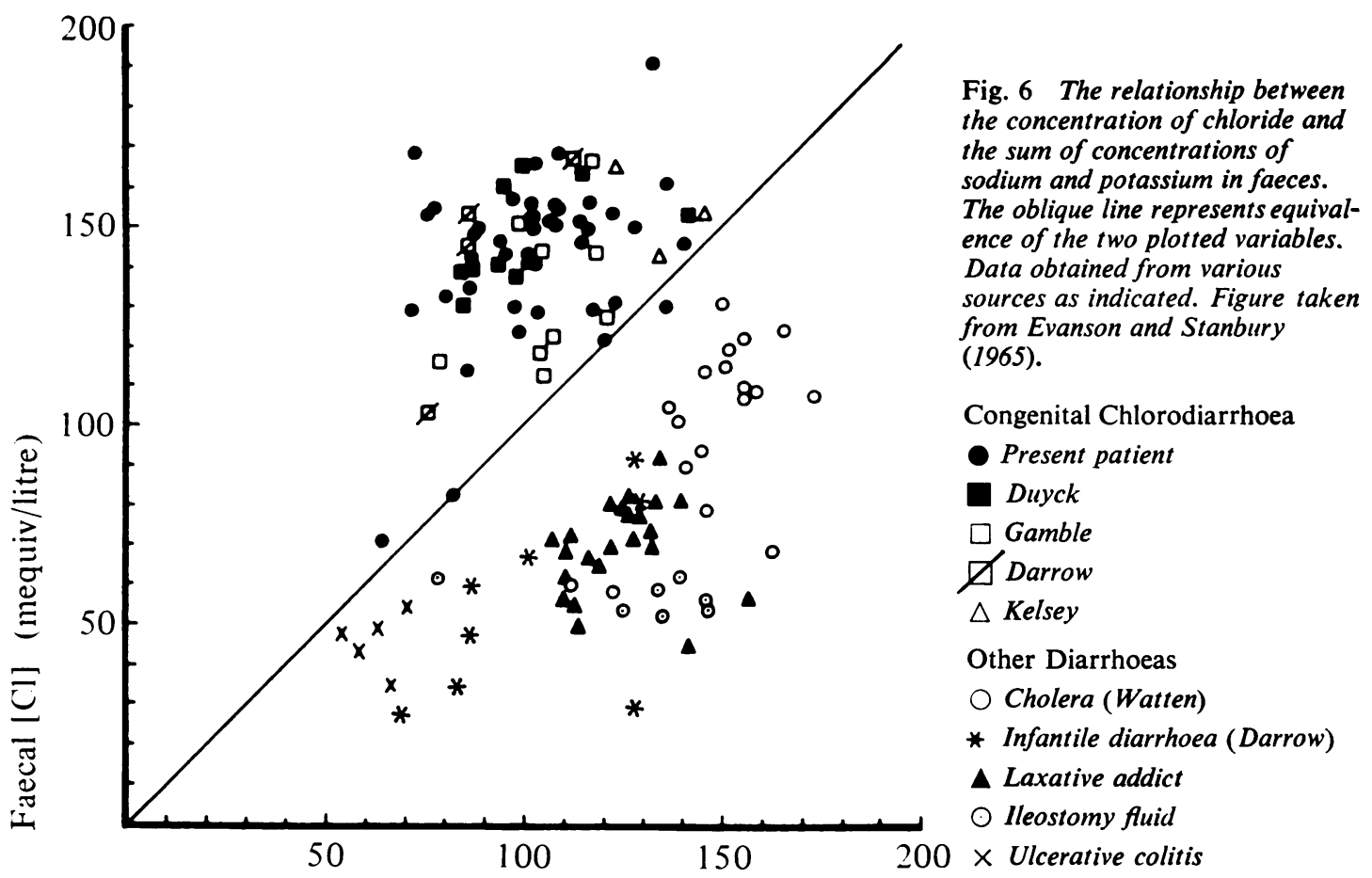

Faecal $[\mathrm{Na}]+[\mathrm{K}]$ (mequiv/litre)

illustrated in Fig. 5, an episode of salt depletion was associated with a considerable increase in potassium loss in ileostomy effluent and this was reversed by replacing sodium. In another subject, with laxativeinduced diarrhoea, potassium deficiency was greatly aggravated by excessive aldosterone secretion and was partially reversed by treatment with spironolactone (Fleischer, Brown, Graham, and Delena, 1969).

There are few known derangements of ileocolonic absorption of water and ions. Extensive inflammatory bowel disease, such as ulcerative colitis and Crohn's disease of the colon, is associated with diminished absorption of sodium, chloride, and water, and increased potassium secretion into the lumen (Harris and Shields, 1970; Head, Heaton, and Kivel, 1969). Bile salts may enter the colon in greatly increased amounts if the normal ileal absorbing site is resected or bypassed. Deconjugated bile acids, produced by bacterial metabolism, inhibit colonic absorption of water and sodium (Mehkjian and Phillips, 1970) and may be responsible for the severe fluid diarrhoea sometimes observed in patients after ileal resection (Hofmann, 1967). Bile salts may be bound in the lumen and rendered ineffective by the anion-exchange resin cholestyramine, which has been used with some success to control gut losses of fluid in such patients (Hofmann and Poley, 1969).

The only apparently specific disturbance of ion transport in this region is the rare condition of congenital chloride diarrhoea (Evanson and Stanbury, 1965). In this disorder, fluid diarrhoea is present from birth and the stool chloride concentration is characteristically greater than the sum of sodium and potassium concentrations (Fig. 6). This results in episodes of severe dehydration, accompanied by hypochloraemic alkalosis and the absence of chloride in the urine. Recent perfusion studies in two cases have shown that the jejunal absorption of water and ions is normal, whereas the ileum and colon cannot absorb chloride or secrete bicarbonate (Pearson, Sladen, Edmonds, Wills, Tavill, and McIntyre, 1970) and may actually secrete chloride into the lumen (Turnberg, 1971). It is not clear if this is the result of a disturbance in the permeability of the mucosa to the chloride ion or whether it respresents a deficiency of specific chloride transport mechanism(s). Sodium absorption by the ileum and colon is greatly impaired by the absence of a readily available anion, but is not completely abolished. Potassium deficiency is 
common and may prove difficult to correct. However, reversal of potassium deficiency may apparently result in increased gut absorption of chloride in these patients (Evanson and Stanbury, 1965). There is also some evidence to suggest that chloride diarrhoea may be acquired in some patients with potassium deficiency and, usually, severe gut disease (Lancet, 1966). However, this is not a well recognized or established syndrome and the effects of potassium deficiency on the handling of fluid and ions by the human gut have not apparently been investigated.

\section{Conclusions}

In summary, absorption of water sodium and chloride by the small and large intestine plays an important role in the total conservation of fluid and electrolytes by the body. Most absorption takes place in the jejunum in association with specific absorption mechanisms for bicarbonate and a variety of nonelectrolytes, especially sugars and amino acids. The ileum and colon have an independent absorbing mechanism for sodium and water, under the influence of aldosterone, which efficiently conserves the fluid remaining in the intestinal lumen after the various products of digestion have been absorbed. Failure of these mechanisms may result in considerable losses of fluid and ions, with consequent dehydration and a variety of acid-base disturbances. However, there are few recognized syndromes in which defects of ion transport are of primary importance.

\section{References}

Adibi, S. A. (1970). Leucine absorption rate and net movements of sodium and water in human jejunum. J. appl. Physiol., 28, 753-757.

Barry, R. J. C., Smyth, D. H., and Wright, E. M. (1965). Shortcircuit current and solute transfer by rat jejunum. J. Physiol. (Lond.), 181, 410-431.

Billich, C. O., and Levitan, R. (1969). Effects of sodium concentration and osmolality on water and electrolyte absorption from the intact human colon. J. clin. Invest., 48, 1336-1347.

Borgström, B., Dahlqvist, A., Lundh, G., and Sjövall, J. (1957). Studies of intestinal digestion and absorption in the human. J. clin. Invest., 36, 1521-1536.

Clarke, A. M., Chirnside, A., Hill, G. L., Pope, G., and Stewart, M. K. (1967). Chronic dehydration and sodium depletion in patients with established ileostomies. Lancet, 2, 740-743.

Code, C. F. (1962). Normal rates of absorption of water, sodium and potassium in man and animal. Amer. J. dig. Dis., 7, 50-56.

Crane, R. K. (1965). $\mathrm{Na}^{+}$-dependent transport in the intestine and other animal tissues. Fed. Proc., 24, 1000-1006.

Curran, P. F. (1968). Water absorption from the intestine. Amer. J. clin. Nutr., 21, 781-784.

Devroede, G. J., and Phillips, S. F. (1969). Conservation of sodium, chloride and water by the human colon. Gastroenterology, 56, 101-109.

Devroede, G. J., and Phillips, S. F. (1970). Failure of the human rectum to absorb electrolytes and water. Gut, 11, 438-442.

Edmonds, C. J., and Godfrey, R. C. (1970). Measurement of electric potentials of the human rectum and pelvic colon in normal and aldosterone-treated patients. Gut, 11, 330-337.
Elias, B., Gibson, G. T., Greenwood, L. F., Hunt, J. N., and Tripp, J. H. (1968). The slowing of gastric emptying by monosaccharides and disaccharides in test meals. J. Physiol. (Lond.), $\underset{\sim}{\vec{\gamma}}$ 194, 317-326.

Evanson, J. M., and Stanbury, S. W. (1965). Congenital chloridorrhoea or so-called congenital alkalosis with diarrhoea. Gut, 6, 29-38.

Fleischer, N., Brown, H., Graham, D. Y., and Delena, S. (1969).ర Chronic laxative-induced hyperaldosteronism and hypo- $\frac{\bar{O}}{\sigma}$ kalaemia simulating Bartter's syndrome. Ann. intern. Med., 70, 791-798.

Fordtran, J. S., and Dietschy, J. M. (1966). Water and electrolyte $\underset{\mathbb{D}}{\vec{D}}$ movement in the intestine. Gastroenterology, 50, 263-285.

Fordtran, J. S., and Ingelfinger, F. J. (1968). Absorption of water, 幽 elestrolytes and sugars from the human gut. In Handbook of Physiology, section 6, vol. 3, pp. 1457-1490, edited by C. F. $\overrightarrow{0}$ Code. American Physiological Society, Washington DC.

Fordtran, J. S., and Locklear, T. W. (1966). Ionic constituents and $\overrightarrow{\vec{\omega}}$ osmolality of gastric and small intestinal fluids after eating. Amer. J. dig. Dis., 11, 503-521.

Fordtran, J. S., Rector, F. C., Jr., and Carter, N. W. (1968). The용 mechanisms of sodium absorption in the human small intestine. is
$J$. clin. Invest., 47, 884-900.

Geall, M. G., Spencer, R. J., and Phillips, S. F. (1969). Transmural '̇ electrical potential difference of the human colon. Gut, 10, 921-923.

Giller, J., and Phillips, S. F. (1970). Colonic absorption of electrolytes $\mathscr{Q}$ and water in man: a comparison of 24 hour ileal content and $O$ faeces. (Abstr.) Gastroenterology, 58, 951.

Goulston, K., Harrison, D. D., and Skyring, A. P. (1963). Effect of mineralocorticoids on the sodium/potassium ratio of human $C$ ileostomy fluid. Lancet, 2, 541-542.

Harris, J., and Shields, R. (1970). Absorption of water and electrolytes by the intact human colon in diffuse untreated proctocolitis. Gut, 11, 27-3j.

Head, L. A., Heaton, J. W., and Kivel, R. M. (1969). Absorption of water and electrolytes in Crohn's disease of the colon. Gastro- $\bullet$ enterology, 56, 571-579.

Hindle, W., and Code, C. F. (1962). Some differences between dưodenal and ileal sorption. Amer. J. Physiol., 203, 215-220.

Hirschhorn, N., Kinzie, J. L., Sachar, D. B., Northrup, R. S., Tayl⿳亠丷⿵冂. J. O., A hmad, S. Z., and Phillips, R. A. (1968). Decrease in ne stool output in cholera during intestinal perfusion with glucose-containing solutions. New Engl. J. Med., 279, 176-181.

Hofmann, A. F. (1967). Syndrome of ileal disease and broken enterohepatic circulation: cholerheic enteropathy. Gastroenterology, $52,752-757$.

Hofmann, A. F., and Poley, J. R. (1969). Cholestyramine treatment of diarrhoea associated with ileal resection. New Engl. J. Med., 281, 397-402.

Holdsworth, C. D., and Dawson, A. M. (1964). The absorption of monosaccharides in man. Clin. Sci., 27, 371-379.

Hunt, J. N. (1956). Some properties of an alimentary osmoreceptor mechanism. J. Physiol. (Lond.), 132, 267-288.

Kraft, A. R., Tompkins, R. K., and Zollinger, R. M. (1970). Recognition and management of the diarrhoeal syndrome caused by nonbeta islet cell tumours of the pancreas. Amer. J. Surg., 119, 163-169.

Kramer, P. (1966). The effect of varying sodium loads on the ileal excreta of human ileostomised subjects. J. clin. Invest., 45, $1710-1718$

Kramer, P., Kearney, M. M., and Ingelfinger, F. J. (1962). The effects of specific foods and water loading on the ileal excreta of $D$ ileostomised human subjects. Gastroenterology, 42, 535-545.

Lancet (1966). Diarrhoea and acid-base disturbances. (Leader). Lancet, 1, 1305-1306.

Launiala, K. (1968). The mechanism of diarrhoea in congenital disaccharide malabsorption. Acta paediat. scand., 57, 425-432.

Levitan, R. (1967). Salt and water absorption from the normal human colon: effect of 9-alpha-fluorohydrocortisone administration. J. Lab. clin. Med., 69, 558-564.

Levitan, R., and Ingelfinger, F. J. (1965). Effect of $\gamma$-aldosterone on salt and water absorption from intact human colon. J. clin. Invest., 44, 801-808.

Love, A. H. G., Mitchell, T. G., and Phillips, R. A. (1968). Water and sodium absorption in the human intestine. J. Physiol. (Lond.), 195, 133-140.

Mehkjian, H. S., and Phillips, S. F. (1970). Perfusion of the canine colon with unconjugated bile acids. Effect on water and 
electrolyte transport, morphology and bile acid absorption. Gastroenterology, 59, 120-129.

McMichael, H. B., Webb, J., and Dawson, A. M. (1967). The absorption of maltose and lactose in man. Clin. Sci., 33, 135-145.

Nalin, D. R., Cash, R. A., Rahman, M., and Yunus, M. (1970). Effect of glycine and glucose on sodium and water absorption in patients with cholera. Gut, 11, 768-772.

Olsen, W. A., and Ingelfinger, F. J. (1968). The role of sodium in intestinal glucose absorption in man. J. clin. Invest., 47, 11331142.

Pearson, A. J. G., Sladen, G. E., Edmonds, C. J., Wills, M. R., Tavill, A. S., and McIntyre, N. (1970). Congenital chloridorrhoea: the nature of the defect. (Abstr.) Gut, 11, 370.

Phillips, S. F., and Summerskill, W. H. J. (1967). Water and electrolyte transport during maintenance of isotonicity in human jejunum and ileum. J. Lab. clin. Med., 70, 686-698.

Reitemeyer, R. J., Code, C. F., and Orvis, A. L. (1957). Comparison of rate of absorption of labelled sodium and water from upper small intestine of healthy human beings. J. appl. Physiol., 10, 256-260.

Rubinstein, R., Howard, A. V., and Wrong, O. M. (1969). In vivo dialysis of faeces as a method of stool analysis. IV. The organic anion component. Clin. Sci., 37, 549-564.

Schultz, S. G., and Zalusky, R. (1964). Ion transport in isolated rabbit ileum. II. The interaction between active sodium and active sugar transport. J. gen. Physiol., 47, 1043-1059.

Schultz, S. G., and Zalusky, R. (1965). Interactions between active sodium transport and active amino-acid transport in isolated rabbit ileum. Nature (Lond.), 205, 292-294.

Sessions, R. T., Reynolds, V. H., Ferguson, J. L., and Scott, H. W. (1962). Correlation between intraduodenal osmotic pressure changes and $\mathrm{Cr}^{51}$ blood volumes during induced dumping in men with normal stomachs. Surgery, 52, 266-279.

Shields, R., and Miles, J. B. (1965). Absorption and secretion in the large intestine. Postgrad. med. J., 41, 435-439.

Shields, R., Miles, J. B., and Gilbertson, C. (1968). Absorption and secretion of water and electrolytes by the intact colon in a patient with primary aldosteronism. Brit. med. J., 1, 93-96.

Sircus, W., Brunt, P. W., Walker, R. J., Small, W. P., Falconer, C. W. A., and Thomson, C. G. (1970). Two cases of 'pancreatic cholera' with features of peptide-secreting adenomatosis of the pancreas. Gut, 11, 197-205.

Sladen, G. E., and Dawson, A. M. (1968). Effect of bicarbonate on sodium absorption by the human jejunum. Nature (Lond.), 218, 267-268.

Sladen, G. E., and Dawson, A. M. (1969a). Interrelationships between the absorption of glucose, sodium and water by the normal human jejunum. Clin. Sci., 36, 119-132.

Sladen, G. E., and Dawson, A. M. (1969b). Cholera-a clue to functional diarrhoea? Gut, 10, 82-84.

Turnberg, L. A., Fordtran, J. S., Carter, N. W., and Rector, F. C., Jr. (1970). Mechanism of bicarbonate absorption and its relationship to sodium transport in the human jejunum. J. clin. Invest., 49, 548-556.

Turnberg, L. A. (1971). Chloridorrhoea. Proc. roy. Soc. Med. (In press.)

Watten, R. H., Morgan, F. M., Songkhla, Y. N., Vanikiati, B., and Phillips, R. A. (1959). Water and electrolyte studies in cholera. J. clin. Invest., 38, 1879-1889.

Whalen, G. E., Harris, J. A., Geenen, J. E., and Soergel, K. H. (1966). Sodium and water absorption from the human small intestine. The accuracy of the perfusion method. Gastroenterology, 51, 975-984.

Wilson, T. H. (1962). Intestinal Absorption, pp. 134-135. W. B. Saunders, Philadelphia and London.

Wright, H. K., Cleveland, J. C., Tilson, M. D., and Herskovic, T. (1969). Morphology and absorptive capacity of the ileum after ileostomy in man. Amer. J. Surg., 117, 242-244.

Wrong, O., Morrison, R. B. I., and Hurst, P. E. (1961). A method of obtaining faecal fluid by in vivo dialysis. Lancet, 1, 1208-1209.

Wrong, O., Metcalfe-Gibson, A., Morrison, R. B. I., Ng, S. T., and Howard, A. V. (1965). In vivo dialysis of faeces as a method of stool analysis. I. Technique and results in normal subjects. Clin. Sci., 28, 357-375. 